\title{
Investigation of the Efficiency of Small-Scale NF/RO Seawater Desalination by Using Artificial Neural Network Modeling
}

\author{
Asma Adda ${ }^{1}$, Salah Bezari ${ }^{2}$, Mohamed Salmi ${ }^{3,4}$, Giulio Lorenzini ${ }^{5 *}$, Maamar Laidi ${ }^{1}$, Salah Hanini ${ }^{1}$, Rachid Maouedj ${ }^{6}$, \\ Younes Menni ${ }^{7}$, Houari Ameur ${ }^{8}$, Hijaz Ahmad ${ }^{9}$ \\ ${ }^{1}$ Laboratory of Biomaterials and Transport Phenomena (LBMPT), Faculty of Science and Technology, University of Dr Yahia \\ Fares Medea, Medea 26000, Algeria \\ ${ }^{2}$ Unité de Recherche Appliquée en Energies Renouvelables, URAER, Centre de Développement des Energies Renouvelables, \\ CDER, Ghardaïa 47133, Algeria \\ ${ }^{3}$ Department of Physics, University of M'sila, B.P. 1713, M'sila 28000, Algeria \\ ${ }^{4}$ Laboratory of Physics and Chemistry of Materials, University of M'sila, M'sila 28000, Algeria \\ ${ }^{5}$ Department of Engineering and Architecture, University of Parma, Parco Area delle Scienze, 181/A, Parma 43124, Italy \\ ${ }^{6}$ Unité de Recherche en Énergies Renouvelables en Milieu Saharien, URERMS, Centre de Développement des Énergies \\ Renouvelables, CDER, Adrar 01000, Algeria \\ ${ }^{7}$ Unit of Research on Materials and Renewable Energies, Faculty of Sciences, Department of Physics, Abou Bekr Belkaid \\ University, P.O. Box 119-13000-Tlemcen, Algeria \\ ${ }^{8}$ Department of Technology, University Center Salhi Ahmed of Naama (Ctr Univ Naama), B.P. 66, Naama 45000, Algeria \\ ${ }^{9}$ Department of Basic Science, University of Engineering and Technology, Peshawar 25000, Pakistan
}

Corresponding Author Email: Giulio.lorenzini@unipr.it

https://doi.org/10.18280/ijdne.160307

Received: 23 January 2021

Accepted: 11 March 2021

\section{Keywords:}

NF/RO process, permeate water recovery, artificial neural network (ANN)

\begin{abstract}
An attempt is conducted in this paper to develop an artificial neural network (ANN) model for predicting the efficiency of small-scale NF/RO seawater desalination, then applied to the simulation of permeate flow rate and water recovery. A feed-forward backpropagation neural network with the Levenberg-Marquardt learning algorithm is considered. The performance of ANN compared to the multiple linear regression (MLR) is based on the calculated value of the coefficient of determination $\left(R^{2}\right)$. For ANN, $R^{2}$ permeate flow rate was 0.997 , and $R^{2}$ permeate water recovery was 0.999 , and for MLR, $\mathrm{R}^{2}$ permeate flow rate was 0.508 , and $\mathrm{R}^{2}$ permeate water recovery was 0.713 . It was observed that ANN performed better than the MLR.
\end{abstract}

\section{INTRODUCTION}

Nowadays, reverse osmosis membranes are utilized in various applications, such as the treatment of drinking water, wastewater reuse, and seawater desalination [1]. The membrane fouling often causes a limitation of the efficiency of reverse osmosis (RO) membranes in the treatment of water. To reduce or even overcome these limits, several studies have shown that nanofiltration (NF) membrane process is the concurrent technology and can be coupled to reverse osmosis for seawater desalination [2]. Thus, NF is a membrane technology that has positioned between reverse osmosis and ultrafiltration (UF) [3, 4].

Several researchers have tried to increase the water recovery of reverse osmosis systems without reducing the membrane's life $[5,6]$. The performance of NF processes cannot meet drinking water standards because of its inability to reduce salinity in seawater [7-10].

A percentage of $92.8 \%$ for the water recovery was achieved by Drioli et al. $[11,12]$ by integrating the MF-NF-RO with membrane distillation/crystallization system. The adopted system allowed a reduction in the energy consumption of the NF-RO-MC process and the water cost to $1.54-1.61 \mathrm{kWh} \mathrm{m}^{-3}$ and $0.56 \$ / \mathrm{m}^{3}$, respectively. NF is utilized as a pretreatment step of seawater feed and RO or MSF as final treatment step [13]. AlTaee and Sharif [14] carried out the cost analysis on a dual NF-NF, NF-RO, and single RO systems. Their findings indicated that NF-NF combination was the cheapest, followed by RO, then NF-RO systems. In other study by Kaya et al. [15], applicability of NF membranes prior to SWRO system was also investigated. They reported that SWRO flux increased from 30.1 LMH to 55.1 LMH when NF was utilized as a pretreatment before the seawater SWRO unit. The results showed an excellent rejection concerning all ions.

Many works reported the use of ANN to model the nanofiltration (NF) and reverse osmosis (RO) process of seawater desalination separately [16].

In recent years, the utilization of ANN is increasingly successful in various industrial areas [17-23]. The novelty of the current study is to investigate the use of ANNs to model the operation of small-scale NF/SWRO desalination plants to determine the performance of permeate flow rate and permeate water recovery. Moreover, a comparison with the multiple linear regression method (MLR) was made to test the robustness and performance of the ANN model. 


\section{METHODS}

\subsection{Data}

In this study, the database was provided by experimental data available in the literature [24]. A pilot plant testing in which the nanofiltration membrane NF product is sent to the $\mathrm{RO}$ unit and its brine reject is used as make-up to the MSF plant, the NF unit received pre-treated seawater with a temperature feed between $24^{\circ} \mathrm{C}$ and $34^{\circ} \mathrm{C}$ and was operated with operating pressure about 23.54 bar at a recovery of 53-
$57 \%$. The SWRO unit received the NF product as feed, the operating pressure was maintained at 58.84 bar with temperature ranged from 23 to $34^{\circ} \mathrm{C}$, and overall recovery of SWRO system was about $45 \%$. The experimental data is presented in Figure 1.

The selected input parameters included: the feed pressure, temperature, conductivity, flow rate, permeate flow rate, and permeate water recovery. The variation of selected experimental inputs over time is depicted in Figure 2. The values of the standard deviations (STD) are given in Table 1.

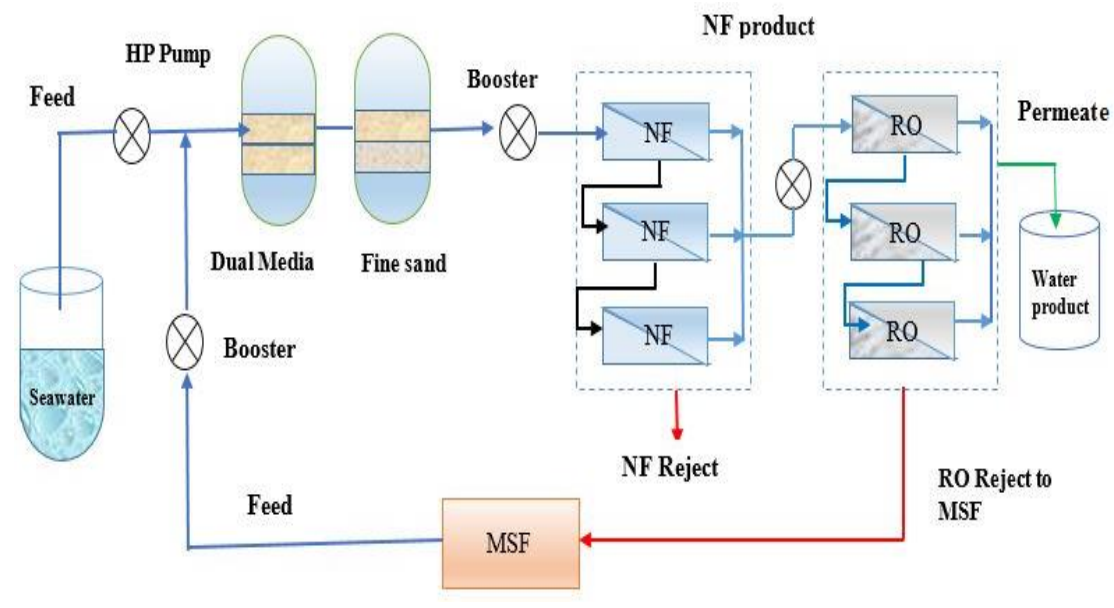

Figure 1. Desalination pilot plant of NF/SWRO

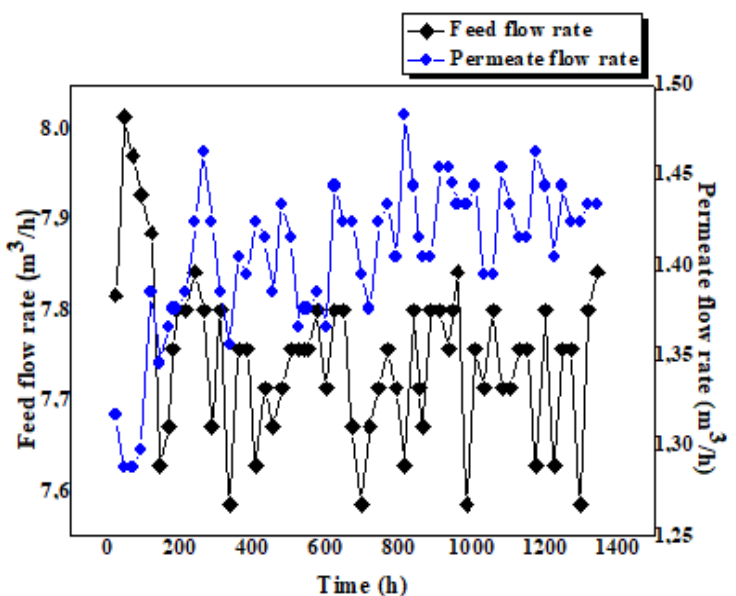

(a)

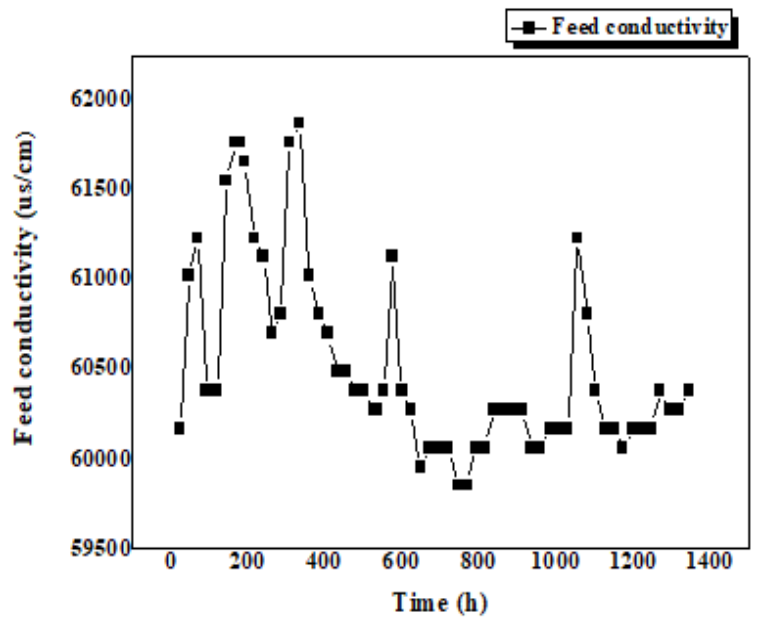

(c)

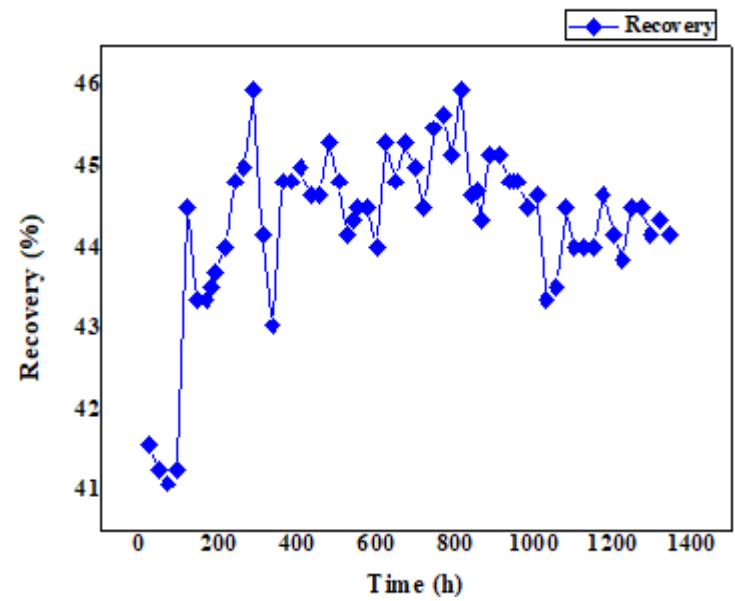

(b)

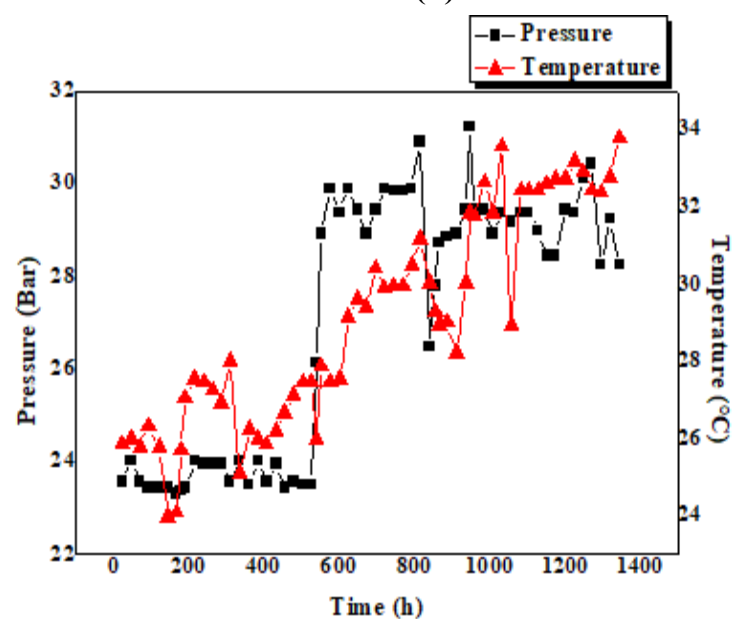

(d)

Figure 2. Performance of NF/SWRO 
Table 1. Parameters statistics of inputs and outputs

\begin{tabular}{cccccccc}
\hline Variable category & Parameters & Symbol & Unit & STD & mean & min & max \\
\hline \multirow{4}{*}{ inputs } & time & $t$ & $\mathrm{~h}$ & 385.92 & 680.317 & 25.197 & 1343.830 \\
\cline { 2 - 7 } & pressure & $p$ & $\mathrm{bar}$ & 2.820 & 27.069 & 23.505 & 31.222 \\
\cline { 2 - 7 } & temperature & $T$ & ${ }^{\circ} \mathrm{C}$ & 2.7422 & 29.063 & 23.968 & 33.789 \\
\cline { 2 - 7 } & feed flow rate & $Q f$ & $\mathrm{~m}^{3} \mathrm{~h}^{-1}$ & 0.088 & 7.748 & 7.586 & 8.014 \\
\cline { 2 - 7 } & feed conductivity & $\delta f$ & $\mu \mathrm{Scm}^{-1}$ & 535.01 & 60519.500 & 59851.06 & 61872.34 \\
\hline \multirow{2}{*}{ outputs } & permeate water recovery & $y$ & $\%$ & 1.018 & 44.308 & 41.093 & 45.951 \\
\cline { 2 - 7 } & permeate flow rate & $Q p$ & $\mathrm{~m}^{3} \mathrm{~h}^{-1}$ & 0.042 & 1.406 & 1.288 & 1.483 \\
\hline
\end{tabular}

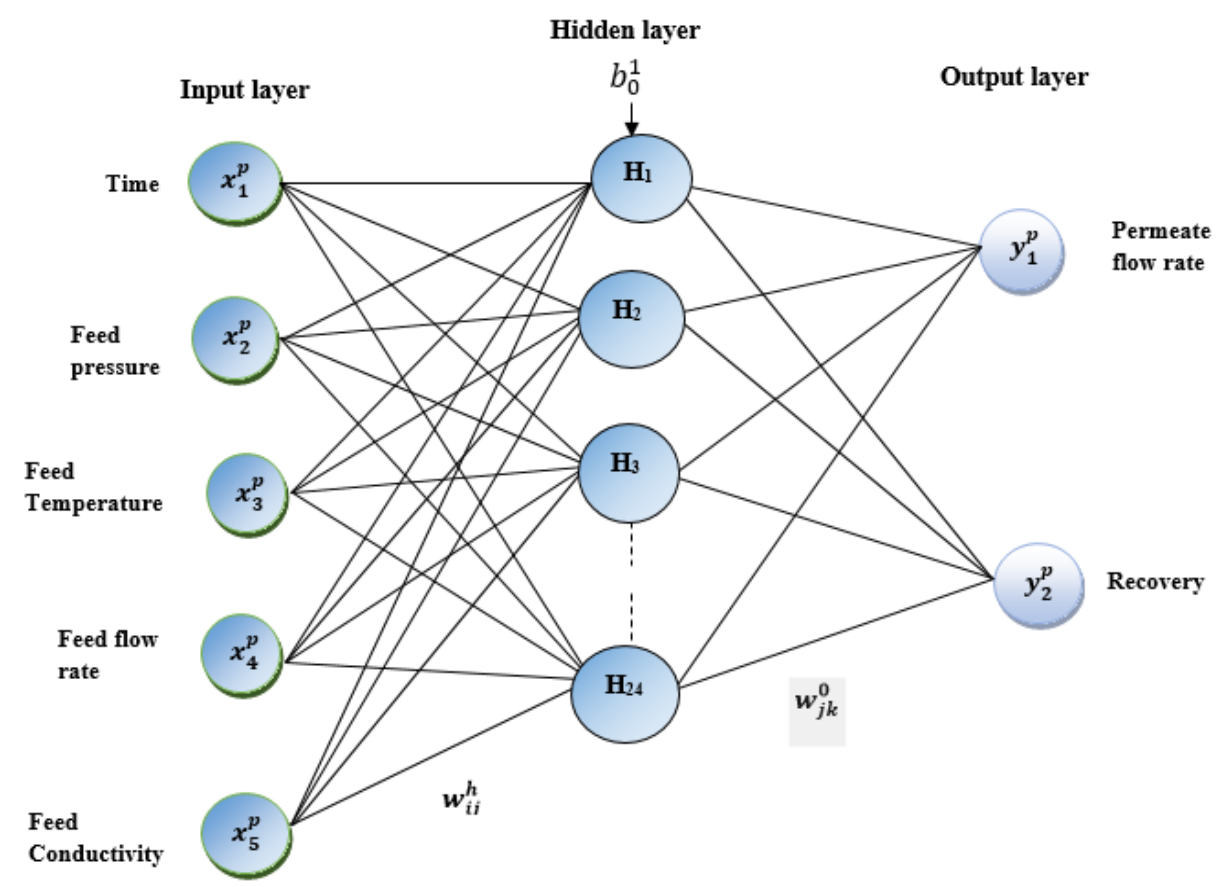

Figure 3. Schematic diagram of an artificial neural network model

\subsection{Modeling development}

To predict the efficiency of the hybrid NF/SWRO desalination system, two approaches were utilized to develop an adequate model to determine the permeate flow rate and water recovery.

\subsubsection{Modeling with multiple linear regression (MLR)}

The linear relationship between the explanatory (independent) variables $\mathrm{xi}$ and response (dependent) $y i$ variables [25] as shown in Eq. (1):

$$
y_{i}=a_{0}+\sum_{i=1}^{n} a_{i} x_{i}
$$

where, yi represents the response or dependent variable (outputs), $x_{i}$ represents the explanatory independent (inputs), and $a_{0}$ represents the constant (intercept). MLR calculations were performed using STATISTICA v. 8.0 (StatSoft, Inc.) software.

\subsubsection{Modeling with neural network}

To construct the ANN model, the database was presented in 75 samples divided into training and test subsets. A training subset has some 60 pieces, which is $80 \%$ of all available data. For the test subset, 15 samples (20\%) have been considered. The neural network-training model was developed by means of a program written in MATLAB software.
The results showed that the optimal fully connected ANN was obtained using 24 neurons in the hidden layer, with high R2 and low RMSE. Different ANN structures with two hidden layers and other neurons in each layer have been tested. It was notable that the ANN with 02 hidden layers can predict the two outputs accurately (Figure 3).

\section{FINDINGS AND ANALYSIS}

\subsection{Validation of the model}

In the training and testing stage, the calculation of errors between the experimental values and prediction is a criterion for evaluating the model and optimum network structure determination.

The correlation coefficient $R_{2}$, the root means square error RMSE (square root of the average sum of squares), and mean absolute error (MAE) are the statistical parameters commonly used in the literature [26-29] for error calculation. They are calculated according to the following equations:

$$
\begin{gathered}
R^{2}=\frac{\sum_{i}\left(y_{\text {exp }}-y_{\text {cal }}\right)^{2}}{\sum_{i}\left(y_{\text {exp }}-\overline{y_{\text {exp }}}\right)^{2}} \\
\text { RMSE }=\sqrt{\frac{1}{N} \sum_{i=1}^{N}\left(y^{\text {exp }}-y^{\text {cal }}\right)^{2}}
\end{gathered}
$$




$$
\mathrm{MAE}=\frac{1}{N} \sum_{i=1}^{N}\left|\left(Y_{\exp }-\mathrm{Y}_{\text {cal }}\right)\right|
$$

where, $N$ is the number of experiments, $y_{\exp }$ is the experimental value for each parameter, $y_{\text {cal }}$ is respectively the predicted value of the $i^{\text {th }}$ experiment calculated by the model for each parameter. $\overline{y_{\text {exp }}}$ and $\overline{y_{\text {cal }}}$ are the arithmetic mean of experimental and calculated values [30-33].

\subsection{Mathematical equations of MLR developed model}

The linear models obtained to determine the permeate flow rate $\left(Q_{p}\right)$ and permeate water recovery $(y)$ are:

$$
\begin{gathered}
Q_{\mathrm{p}}=2.607+0.661 t-0.04 P-0.07 T-0.19 Q_{\mathrm{A}}+0.15 \delta_{\mathrm{A}} \\
(F=14.259, P<0.001) \\
y=101.123+0.542 t-0.124 P-0.51 T-0.34 Q_{\mathrm{A}}-0.27 \delta_{\mathrm{A}} \\
(F=7.609, P<0.001)
\end{gathered}
$$

\subsection{Mathematical equations of ANN developed model}

The proposed neural network model successfully predicts the NF/RO performance parameters i.e. permeate flow rate and permeate water recovery. Integrating all the inputs $x_{i}$ by the mathematical formula is presented as follows. Knowing that $f_{h}$ is the exponential transfer function used in hidden layer:

$$
\begin{gathered}
Z_{j}=f_{h}\left[\sum_{i=1}^{5} w_{j i} x_{i}+b_{j}^{h}\right]=\exp \left(-\sum_{i=1}^{5} w_{j i} x_{i}+b_{j}^{h}\right) \\
j=1,2, \ldots \ldots 24
\end{gathered}
$$

where, $j$ is the number of neurons in the hidden layer $(j=24), i$ is the number of neurons in the input layer $(i=24), w^{I} \quad\left(w_{(j, i)}^{H}\right)$ and $b_{1}^{H}$ are weights and bias between input and hidden layer, $w^{H}\left(w_{(l, j)}^{0}\right)$ and $b_{2}^{0}$ are weights and bias between hidden and output layer, and $l$ is the number of neurons in output layer $(l=2)$. The output $\mathrm{H}$, where $f_{0}$ is the exponential transfer function used in output layer is presented as Eq. (8):

$$
\mathrm{H}=f_{0}\left[\sum_{i=1}^{24} w_{j i}^{H} Z_{i}+b_{2}^{0}\right]
$$

Combining Eqns. (7) and (8) to obtain the relation formula of the output parameters of the ANN as follows:

$$
Q_{\mathrm{p}}, y=\sum_{i=1}^{24} w_{j i}^{H} \exp \left(-\sum_{i=1}^{24} w_{j i} x_{i}+b_{j}^{h}\right)+b_{2}^{0}
$$

The equation of the predicted permeate flow rate $\left(Q_{\mathrm{p}}\right)$ and permeate water recovery $(y)$ is given by the Eq. (9).

\section{COMPARISON}

The results of the ANN model and MLR model were evaluated based on the comparison between the model values predicted and the experimental data using the different statistical parameters as shown in Table 2. The models statistical parameters for the prediction results obtained using MATLAB function "postreg".

In fact, ANN showed a higher regression coefficient value than MLR, as presented in Figure 4. However, for the permeate flow rate and permeate water recovery, the error (MAE and RMSE) of the ANN model is lower than the MLR model. It appears that ANN is more appropriate than MLR. As shown in Figure 5, the result of ANN is a logic that can relatively quickly be reflected on the operating system for $\mathrm{NF} / \mathrm{RO}$ process and the existence of a non-linear correlation between the outputs of the network $\left(Q_{p}\right.$ and $\left.y\right)$ and the experimental variables. On the other hand, the result of MLR cannot be used by the NF/RO operating systems.

Table 2. Comparison of statistical parameters for ANN and MLR model

\begin{tabular}{ccccccc}
\hline & & $\alpha$ & $\beta$ & $R^{2}$ & RMSE & MAE \\
\hline \multirow{2}{*}{ permeate flow rate $/ \mathrm{m}^{3} \mathrm{~h}^{-1}$} & ANN & 0.9988 & 0.0017 & 0.997 & 0.00256 & 0.0014 \\
\cline { 2 - 7 } & MLR & 1 & $2.33 \times 10^{-6}$ & 0.461 & 0.021 & 0.0246 \\
\hline \multirow{2}{*}{ permeate water recover/\% } & ANN & 1.0005 & -0.0212 & 0.999 & 0.0401 & 0.0257 \\
\cline { 2 - 7 } & MLR & 1 & $-7.56 \times 10^{-5}$ & 0.327 & 0.482 & 0.6463 \\
\hline
\end{tabular}
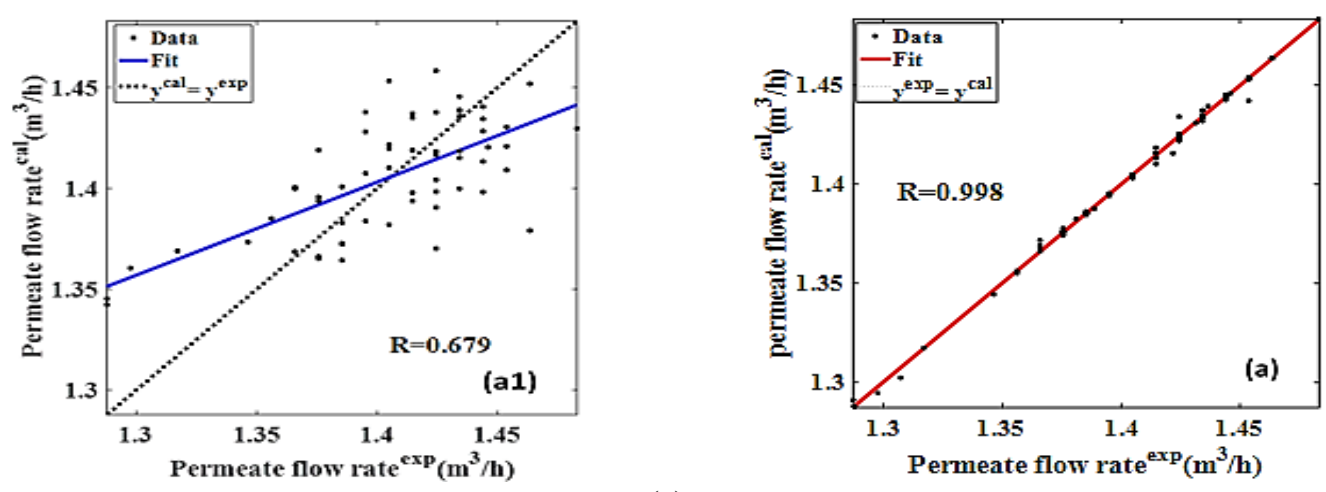

(a) 


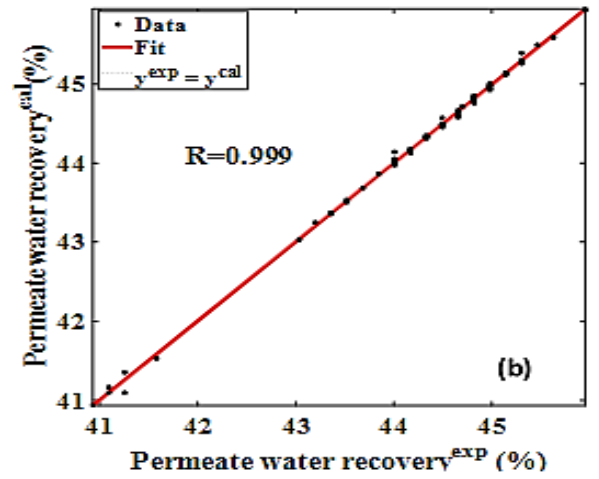

(b)

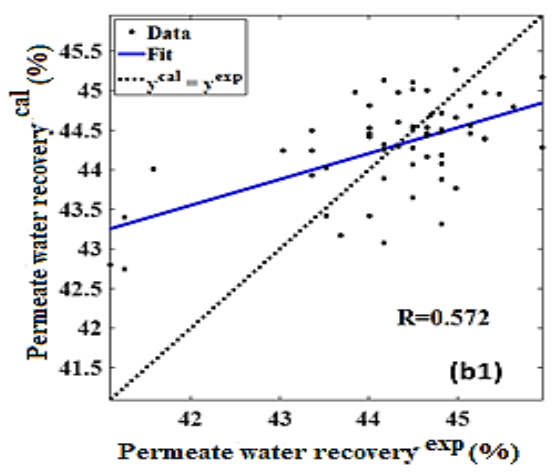

Figure 4. Results from ANN model of (a) permeate flow rate (b) permeate water recovery

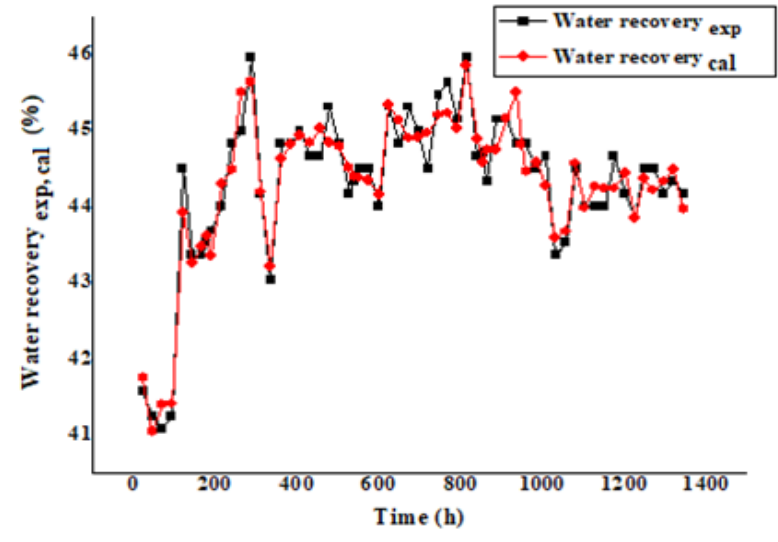

(a)

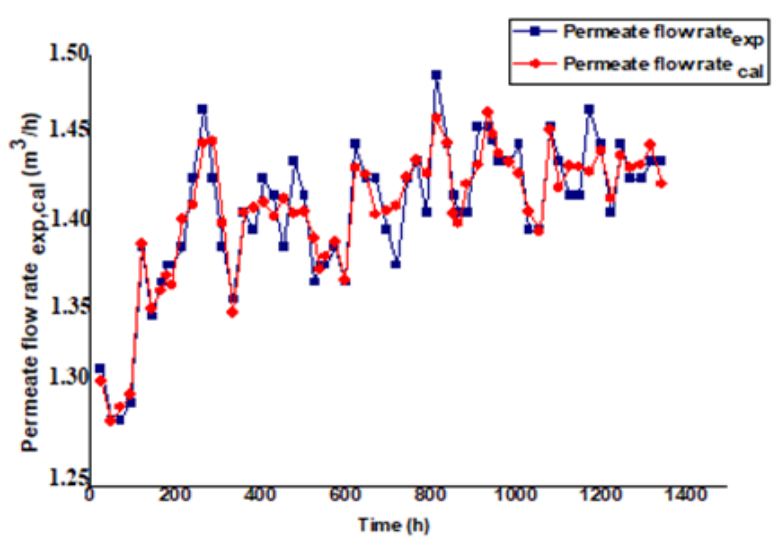

(b)

Figure 5. Validation of the predicted values of (a) permeate flow rate (b) permeate water recovery for NN structure 5-24-2

\subsection{Sensitivity analysis}

To explore the sensitivity of the performance of hybrid $\mathrm{NF} / \mathrm{RO}$ desalination pilot plant to the inputs and to find the most dominant parameters, the weights method was employed in this study.

The relative importance $(\%)$ was calculated based on the Garson equation [34-36] (see Eq. (10)).

$$
R_{I j}=\frac{\sum_{m=1}^{N_{h}}\left(\left(\frac{\left|W_{j m}^{i h}\right|}{\sum_{k=1}^{N_{i}}\left|W_{k m}^{i h}\right|}\right) \times\left|W_{m n}^{h 0}\right|\right)}{\sum_{k=1}^{N_{i}}\left\{\sum_{m=1}^{N_{h}}\left(\frac{\left|W_{k m}^{i h}\right|}{\sum_{k=1}^{N_{i}}\left|W_{k m}^{i h}\right|}\right) \times\left|W_{m n}^{h 0}\right|\right\}}
$$

where, $I_{j}$ is the relative importance of the $j_{t h}$ input variable on the output variable.

According to each input that exceeds $6 \%[28,34]$, all the information has a considerable impact on the output (permeate flow rate and permeate water recovery). In the present study, the time has an effect of about $19 \%$ on both outcomes. The feed pressure $(31.3 \%)$ strongly affects the permeate flow, whereas the feed pressure $(26.6 \%)$ and feed flow rate $(21.7 \%)$ significantly affect the permeate water recovery (Figure 6), which explains that the selected inputs parameters have a substantial effect on the outputs and a great significance in the performance of NF/RO desalination plant.

\section{Permeate flow rate}

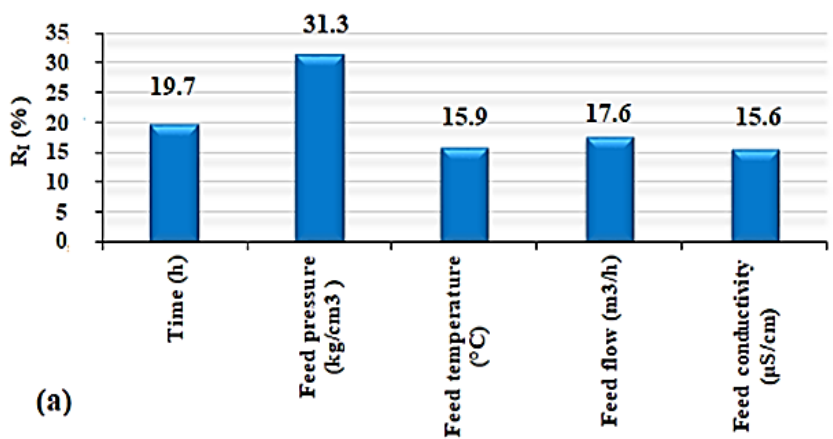

Permeate water l'ecovery

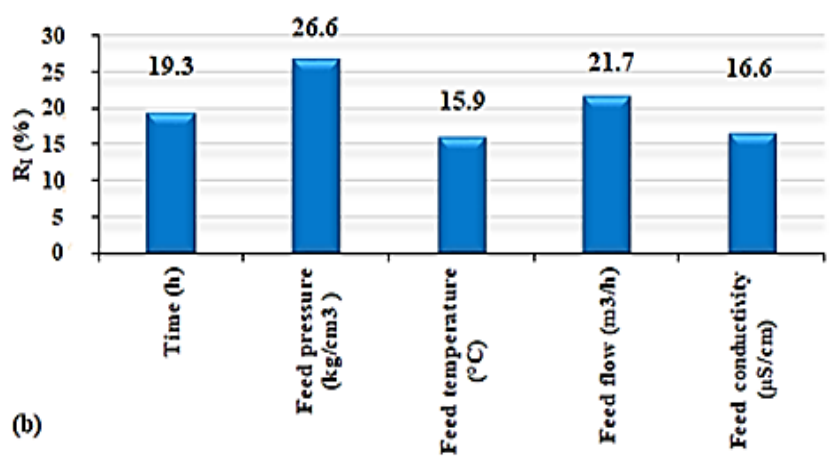

Figure 6. The importance percentage distribution of each inputs variable on: (a) Permeate flow rate and (b) Permeate water recovery 


\section{CONCLUSION}

To predict the efficiency of small-scale NF/SWRO desalination plants, an ANN model was developed for simulation of the permeate flow rate and permeate water recovery. The efficiency of ANN models and MLR models was determined. The inspection of the results from the ANN models with the MLR models revealed that ANN models were good at predicting permeate flow rate and permeate water recovery with high $\mathrm{R}_{2}$ values and low RMSE and MAE values, which implied the robustness of the neural model. Finally, the ANN models can be considered as a powerful tool in predicting the efficiency of the seawater desalination hybrid process NF/RO.

\section{REFERENCES}

[1] Eunsu, L., Lee, S., Hong, S. (2010). A new approach to the characterization of reverse osmosis membrane by dynamic hysteresis, Desalin. Water Treat, 18(1-3): 257263. https://doi.org/10.5004/dwt.2010.1782

[2] Vuong, D.X. (2006). Two stage nanofiltration seawater desalination system. U.S. Patent No. 7,144,511. 2006. https://patents.google.com/patent/US7144511B2/en

[3] Diawara, K.C. (2008). Nanofiltration process efficiency in water desalination. Separ. Purific. Rev., 37(3): 302324. https://doi.org/10.1080/15422110802228770

[4] Hilal, N., Al-Zoubi, H., Darwish, N.A., Mohamma, A.W., AArabi, M. (2004). A comprehensive review of nanofiltration membranes: Treatment, pretreatment, modelling, and atomic force microscopy. Desalination 170(3): 281-308 https://doi.org/10.1016/j.desal.2004.01.007

[5] Fritzmann, C., Löwenberg, J., Wintgens, T., Melin, T. (2007). State-of-the-art of reverse osmosis desalination. Desalination, 216(1-3):

$1-76$. https://doi.org/10.1016/j.desal.2006.12.009

[6] Khawaji, A.D., Kutubkhanah, I.K., Wie, J.M. (2008). Advances in seawaterdesalination technologies. Desalination, 221(1-3): 47-69. https://doi.org/10.1016/j.desal.2007.01.067

[7] Bellona, C., Drewes, J.E. (2005). Role of membrane surface charge and solute physicochemical properties in the rejection of organic acids by NF membranes. J. Membr. $\quad$ Sci., 249(1-2): 227-234. https://doi.org/10.1016/j.memsci.2004.09.041

[8] M'nif, A., Bouguecha, S., Hamrouni, B., Dhahbi, M. (2007). Coupling of membrane processes for brackish water desalination. Desalination, 203(1-3): 331-336. https://doi.org/10.1016/j.desal.2006.04.016

[9] Hassan, A.M., Farooque, A.M., Jamaluddin, A.T.M., AlAmoudi, A.S., Al-Sofi, M.A.K., Rubaian, A.F., Gurashi, M.M., Kither, N.M., Dalvi, A.G.I., Al-Tisan, I.A.R. (1999). Optimization of NF Pretreatment of Feed to Seawater Desalination Plants. Presented at IDA World Congress on Desalination Water Reuse held at San Diego, USA, 29 Aug.-3 Sept. 1999.

[10] Hassan, A.M., Al-Sofi, M.A.K., Farooque, A.M., Dalvi, A.G.I., Jamaluddin, A.T.M., Kither, N.M., AI-Amoudi, A.S., Al-Tisan, I.A.R. (1999). A nano filtration (NF) membrane pretreatment of swro feed and MSF make-up (part - I). 4th WSTA Conference, Bahrain, pp. 13-17.

[11] Drioli, E., Criscuoli, A., Curcio, E. (2002). Integrated membrane operations for seawater desalination. Desalination, 147(1-3): 77-81. https://doi.org/10.1016/S0011-9164(02)00579-9

[12] Drioli, E., Curcio, E., DiProfio, G., Macedonio, F., Criscuoli, A. (2006). Integrating membrane contactors technology and pressure-driven membrane operations for seawater desalination: energy, exergy and costs analysis. Chem. Eng. Res. Des., 84(3): 209-220. https://doi.org/10.1205/cherd.05171

[13] Turek, M., Chorążewska, M. (2004). Nanofiltration process for seawater desalination-salt production integrated system. Desal. Water Treat., 7(1-3): 178-181. https://doi.10.5004/dwt.2009.713

[14] AlTaee, A., Sharif, A.O. (2011). Alternative design to dual stage NF seawater desalination using high rejection brackish water membranes. Desalination, 273(2-3): 391397. https://doi.org/10.1016/j.desal.2011.01.056

[15] Kaya, C., Sert, G., Kabay, N., Arda, M., Yükse, M., Egemen, Ö. (2015). Pretreatment of nanofiltration (NF) in seawater Desalination-Preliminary integrated membrane tests in Urla. Turkey. Desalination, 369: 1017. https://doi.org/10.1016/j.desal.2015.04.029

[16] Kaya, C., Jarma, Y.A., Guler, E., Kabay, N., Arda, M., Yükse, M. (2019). Seawater desalination by using nanofiltration (NF) and brackish water reverse osmosis (BWRO) membranes in sequential mode of operation. J. Membr. Sci. Resear., 6(1): 40-46. https://doi.org/10.22079/JMSR.2019.107844.1264

[17] Suykens, J.A., Vandewalle, J.P., De Moor, B.L.R. (1996). Artificial neural networks for modelling and control of non-linear systems. Springer Science \& Business Media. https://doi.org/10.1007/978-1-4757-2493-6

[18] El-Hawary, M.E. (1993). Artificial neural networks and possible applications to desalination. Desalination, 92(1$3)$ : $\quad$ 125-147. https://doi.org/10.1016/00119164(93)80078-2

[19] Murthy, Z.V.P., Vora, M.M. (2004). Prediction of reverse osmosis performance using artificial neural network. Indian J. Chem. Technol., 11(1): 108-115.

[20] Abbas, A., Al-Bastaki, N. (2005). Modeling of an RO water desalination unit using neural networks. Chem. Eng. $\quad$ J., 114(1-3): 139-143. https://doi.org/10.1016/j.cej.2005.07.016

[21] Lee, Y.G., Lee, Y.S., Jeon, J.J., Lee, S., Yang, D.R., Kim, I.S., Kim, J.H. (2009). Artificial neural network model for optimizing operation of a seawater reverse osmosis desalination plant. Desalination, 247(1-3): 180-189. https://doi.org/10.1016/j.desal.2008.12.023

[22] Soleimani, R., Shoushtari, N.A., Mirza, B., Salahi, A. (2013). Experimental investigation, modeling and optimization of membrane separation using artificial neural network and multi-objective optimization using genetic algorithm. Chem. Eng. Res. Des., 91(5): 883-903. https://doi.org/10.1016/j.cherd.2012.08.004

[23] Aish, A.M., Zaqoot, H.A., Abdeljawad, S.M. (2015). Artificial neural network approach for predicting reverse osmosis desalination plants performance in the Gaza Strip. Desalination, 367: 240-247. https://doi.org/10.1016/j.desal.2015.04.008

[24] Hamed, O.A., Hassan, A.M., Al-Shail, K., Farooque, M.A. (2009). Performance analysis of a trihybrid NF/RO/MSF desalination plant. Desal. Water Treat., 1(1-3): 215-222. https://doi.org/10.5004/dwt.2009.113

[25] Ge, Y., Wu, H. (2019). Prediction of corn price 
fluctuation based on multiple linear regression analysis model under big data. Neural. Comput. Appl., 32: $16843-$ 16855. https://doi.org/10.1007/s00521-018-03970-4

[26] Bhagat, P. (1990). An introduction to neural nets. Chem. Eng. Prog., 86: 55-60.

[27] Tambe, S.S., Kulkami, B.D., Deshpande, P.B. (1996). Elements of Artificial Neural Networks with Selected Applications in Chemical Engineering, and Chemical and Biological Sciences, Simulation and Advanced Controls, Ltd., Louisville, KY, USA (1996).

[28] Adda, A., Hanini, S., Abbas, M., Sediri, M. (2019). Novel adsorption model of filtration process in polycarbonate track-etched membrane: Comparative study. Environ. Eng. Res., 25(4): 479-487. https://doi.org/10.4491/eer.2019.136

[29] Maouz, H., Khaouane, L., Hanini, S., Ammi, Y., Hamadache, M., Laidi, M. (2020). QSPR studies of carbonyl, hydroxyl, polyene indices, and viscosity average molecular weight of polymers under photostabilization using ANN and MLR approaches. Kem. $\quad$ Ind., $69(1-2)$ : https://doi.org/10.15255/KUI.2019.022

[30] Zare, A.H., Bayat, V.M., Daneshkare, A.P. (2011). Forecasting nitrate concentration in groundwater using artificial neural network and linear regression models. Int. Agrophys., 25(2): 187-192.

[31] Keskes, S., Hanini, S., Hentabli, M., Laidi, M. (2020). Artificial intelligence and mathematical modelling of the drying kinetics of pharmaceutical powders. Kem. Ind., $69 \quad(3-4)$ : 137-152. https://doi.org/10.15255/KUI.2019.038

[32] Melzi, N., Khaouane, L., Ammi, Y., Hanini, S., Laidi, M., Zentou, H. (2019). Comparative study of predicting the molecular diffusion coefficient for polar and non-polar binary gas using neural networks and multiple linear regressions. Kem. Ind., 68(11-12): 573-582. https://doi.org/10.15255/KUI.2019.010

[33] Ammi, Y., Khaouane, L., Hanini, S. (2020). A comparison of neural networks and multiple linear regressions models to describe the rejection of micropollutants by membranes. Kem. Ind., 69(3-4): 111127. https://doi.org/10.15255/KUI.2019.024

[34] Garson, G.D. (1991). Interpreting neural network connection weights. AI Ex., 6(4): 47-51.

[35] Goh, A.T.C. (1995). Back-propagation neural networks for modeling complex systems. Artif. Intell. Eng., 9(3): 143-151. https://doi.org/10.1016/0954-1810(94)00011-S

[36] Laidi, M., Hanini, S. (2013). Optimal solar COP prediction of a solar-assisted adsorption refrigeration system working with activated carbon/methanol as working pairs using direct and inverse artificial neural network. Inter. J. Refrig., 36(1): 247-257. https://doi.org/10.1016/j.ijrefrig.2012.09.016

\section{NOMENCLATURE}

$\begin{array}{ll}\text { ANN } & \text { artificial neural network } \\ b & \text { bias factor } \\ H & \text { output function } \\ \text { MAE } & \text { mean absolute error } \\ \text { MLR } & \text { multiple linear regression } \\ \text { MSF } & \text { multi-stage flash } \\ \text { NF } & \text { nanofiltration membrane } \\ P & \text { pressure, bar } \\ Q & \text { flow rate, } \mathrm{m}^{3} \mathrm{~h}^{-1} \\ R^{2} & \text { regression coefficient } \\ R_{I} & \text { relative importance, } \% \\ \mathrm{RMSE} & \text { root mean square error } \\ t & \text { time, } \mathrm{h} \\ T & \text { temperature, }{ }^{\circ} \mathrm{C} \\ w & \text { weight factor } \\ x & \text { sigmoid function } \\ y & \text { permeate water recovery, } \% \\ Z & \text { transfer function in the hidden layer }\end{array}$

\section{Greek symbols}

$\begin{array}{ll}\delta & \text { conductivity, } \mu \mathrm{S} \mathrm{cm}^{-1} \\ \alpha & \text { intercept } \\ \beta & \text { slope }\end{array}$

\section{Subscripts}

$\begin{array}{ll}\text { exp } & \text { exponential } \\ f & \text { feed } \\ i & \text { number of neurons in the input layer } \\ h & \text { number of neurons in the hidden layer } \\ p & \text { permeate }\end{array}$

